\title{
Analysis of reliability numerical simulation of long-span steel trussed arch bridge in construction stage
}

\author{
CAl Lurong1, a, Li Yinghua2, b \\ ${ }^{1}$ School of transportation and civil engineering \& Architecture, Foshan University, Foshan \\ 528000, China; \\ ${ }^{2}$ shixing local highway management station, Shaoguan, 512500 \\ acailurong304@163.com, b418474986@qq.com
}

Keywords: Steel trussed arch bridge; reliability numerical simulation; construction stage; optimal internal force state.

\begin{abstract}
At present, the safety evaluation of long-span bridges in construction is a hot research topic in the world. Considering the main factors (cantilever erection, wind load and temperature change), which influence the change of bridge member stress during the construction phase, the reliability of construction stage of the bridge is analyzed by simulation. Then the reliability value of the main arch root of the bridge main span under the most unfavorable load condition is acquired, and the optimal internal force state is determined when the closure construction of the bridge is finished.
\end{abstract}

\section{Introduction}

At present, the steel truss arch bridge construction stage control technology has been studied in-depth by many scholars and is relatively mature [1-2]. However, there are few reports on the reliability evaluation of construction stage of this type bridge. As the statistical variations of materials could make additional error in the prediction and the control of errors, Taejun Cho and Tae Soo Kim [3] developed a probabilistic risk assessment technique and done finite element analysis for the construction phases of an example suspension bridge, and compared the analyzed results with the conventional safety indices and allowable error for the control of deformations during construction. To evaluate the reliability of long span steel arch bridges against wind-induced stability failure during construction, Jin Cheng and Q.S. Li [4] proposed an efficient and accurate algorithm to evaluate the reliability of long span steel arch bridges against wind-induced stability failure during construction.

To sum up, the achievements of safety assessment of construction stage of large-span steel trussed arch bridge are relatively less. Therefore, based on the numerical simulation software and the measured temperature and wind speed data,we suggest a safety assessment method to do safety assessment of the construction stage of the bridge under the most unfavorable stress state. This method can be used to evaluate the internal force state in each construction stage, and it can ensure the optimal security level of the internal force state of this type bridge when the closure construction of the bridge is finished.

\section{The bridge example}

The bridge adopted in this paper is a passenger dedicated line and double line railway bridge. The main bridge is consist of three span continuous through type steel trussed girder flexible arch structure, and steel beam is with a total length $662 \mathrm{~m}$, and span settings form is $110 \mathrm{~m}+2 \times 220$ 
$\mathrm{m}+110 \mathrm{~m}$. The steel trussed beam of the bridge adopts the $N$ type triangular truss with vertical rod, and the internode length is $11.0 \mathrm{~m}$. Among them, the height of the truss of the side span 10 internodes is $15.0 \mathrm{~m}$ and the width is $15.0 \mathrm{~m}$, and the angle of the tilted belly poles is 53.7 degrees; the flexible arch rib is arranged by quadratic parabola; the vector height is $44 \mathrm{~m}$; the rise-span ratio is $1 / 5$. The structure of the bridge is mainly composed by the main truss, arch rib, steel bridge deck system, vertical coupling system, portal frame and sway bracing etc. The main bridge facade layout is shown in Figure 1.

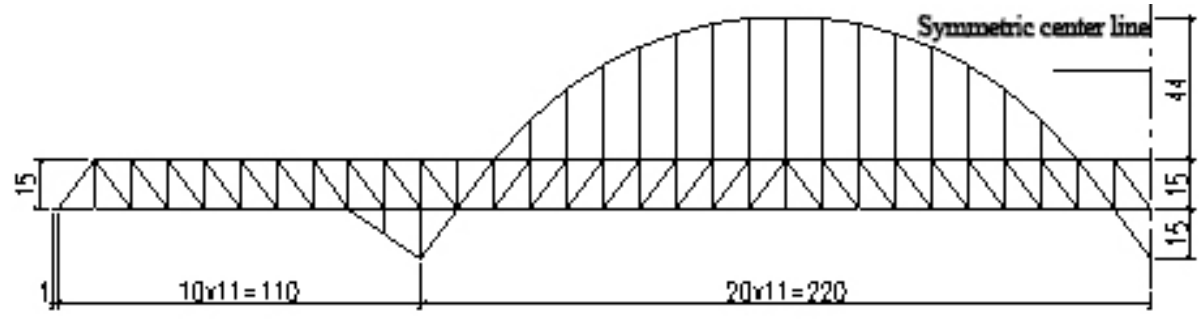

Figure 1 The main bridge facade layout (unit: m)

\section{The safety assessment method}

At present, the First-order Second Moment (FOSM) method for the structural reliability calculation is widely used. According to this method, the failure probability $P_{f}$ (or safety index $\beta$ ) of the structural components can be evaluated by means of considering both the member resistance $R$ and the load effects $S$ as random variables and can be written as:

$P_{f}=\iint_{r-s<0} f_{R}(r) f_{s}(s) d r d s$

In the formula: $f_{R}(r)$ and $f_{s}(s)$ are the probability density functions of $R$ and $S$.

However, the above formula is only appropriate for the condition that the random variables statistic are independent and obey the normal distribution. If $f_{R}(r)$ and $f_{s}(s)$ both obey normal distribution respectively, the calculation formula of the reliability index $\beta$ can be written as:

$\beta=-\Phi^{-1}\left(P_{f}\right)=\left(\mu_{R}-\mu_{S}\right) /\left(\sigma_{R}^{2}+\sigma_{S}^{2}\right)^{1 / 2}$

In the formula: $\Phi^{-1}$ is the inverse function of the standard normal distribution; $\mu_{R}$ and $\mu_{S}$ are the mean of the resistance and load effects respectively; $\sigma_{R}$ and $\sigma_{S}$ are the standard deviation of the resistance and load effects respectively.

For steel bridges, as the applied stresses and stress capacities both are dependent on steel material properties, and the correlation between the applied stresses and stress capacities is basically independent. So, the steel strength probability distribution function is taken as the probability density function of the resistance $R$, which generally obeys Gaussian distribution and can be obtained by in situ material tests, and an equation is used to represent the strength distribution function:

$f_{R}(r)=\frac{1}{\sqrt{2 \pi} \sigma_{r}} e^{-\frac{\left(r-\mu_{r}\right)^{2}}{2 \sigma_{r}^{2}}}$

In the formula: $f_{R}(r)$ is the Gaussian distribution function of the steel strength adopted on the bridge; $\mu_{r}$ is the mean of the steel strength; $\sigma_{r}^{2}$ is the variance of the steel strength.

\section{Results and analysis}

The most unfavorable load condition of the steel truss bridge cantilever erection construction is 
that the cantilever is extended to the temporary pier or bridge pier but not yet supported. Therefore, the most unfavorable load condition of the bridge construction is that the 9th internode construction of the main span main truss of the bridge. Under the condition of the most unfavorable construction condition and the extreme loads, the stress distribution of the checking point is obtained in this paper, seen in Figure 2.

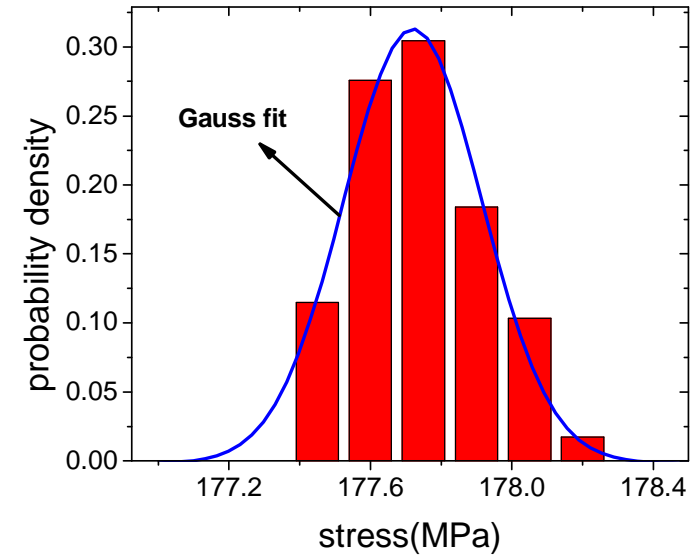

Figure 2 Stress distribution statistics and Gaussian distribution fitting of the FEA data

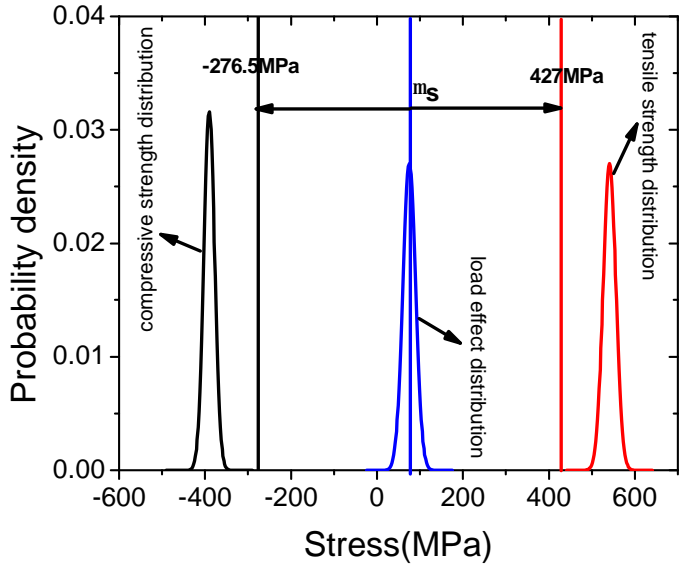

Figure 3 The optimal variation range of the load effect mean after the bridge closure construction

According to the stress distribution shown in Figure 2, it can be seen that the stress distribution of the bridge member in construction stage basically obey Gaussian distribution. Therefore, we use the Gaussian function to fit the stress distribution. According to the formula (2) and the strength parameters in the Table 1, the reliability value of the checking point under the most unfavorable load state can be obtained and is $\beta=16.8$.

Frangopol [5] put forward 5 kinds of bridge reliability status, and assume that the bridge life can be seen as a reliable state process from the intact $(\beta \geq 9.0)$ to the unacceptable $(\beta \leq 4.6)$. In order to make the reliability of the bridge achieve $\beta \geq 9.0$ after the bridge completion, combined formula (2) and the material mechanical property parameters in Table 1, we get that the mean value of the internal force of the bridge closure construction should be maintained in the range: $-276.5 \leq \mu_{s} \leq 427 \mathrm{MPa}$, as shown in Figure 3.

Table 1 The main mechanical property parameters of the steel used on the bridge

\begin{tabular}{cc}
\hline Parameters & Value \\
\hline Compressive Strength & $\mu_{c}=390.56 \mathrm{MPa}, \sigma_{c}=12.61 \mathrm{MPa}$ \\
Tensile Strength & $\mu_{t}=541.11 \mathrm{MPa}, \sigma_{c}=14.74 \mathrm{MPa}$ \\
Young's Modulus & $2.1 \mathrm{e}+11 \mathrm{~Pa}$ \\
Heat transfer coefficient & $1.2 \mathrm{e}-5$ \\
\hline
\end{tabular}

\section{Conclusions}

As for the difficulties of the bridge internal force control strategy in the construction stage, based on the simulation data by Finite element software, this paper put forward a kind of this type bridge security assessment methodology during construction stage, and the main conclusions are as follows: (1) Under the most unfavorable load condition, the reliability of the bridge meets the relevant requirements; (2) The mean value of the internal force of the bridge closure construction should be maintained in the range: $-276.5 \leq \mu_{s} \leq 427 \mathrm{MPa}$. 
However, some important parameter values adopted in this paper should be revised by large number of field test data. The method suggested in this paper can provide a reference to bridge engineers for controlling this type bridge internal force in construction.

\section{References}

[1] Super Long Span Steel Trussed Arch Bridge Construction Control Technology Research Report [R], Wuhan: China and Wuhan harbour engineering design and Research Institute Co., Ltd..2008.

[2] Sun Haitao. Study on key problems of long span steel truss arch bridge [D]. Tongji University, 2006.

[3] Taejun Cho, Tae Soo Kim. Probabilistic risk assessment for the construction phases of a bridge construction based on finite element analysis. Finite Elements in Analysis and Design, 44 (2008), $383-400$.

[4] Jin Cheng and Q.S. Li. Reliability analysis of a long span steel arch bridge against wind-induced stability failure during construction. Journal of Constructional Steel Research, 65 (2009) 552-558.

[5] Frangopol D. M., Das P. C. "Management of bridge stocks based on future reliability and maintenance costs". Current and future trends in bridge design, construction, and maintenance. Thomas Telford, London, 1999, 45-58. 